\title{
RELATIONSHIP OF THE LIGHT INTENSITY OF SELECTED LIGHT CURING UNITS WITH VARYING DISTANCE AND ANGULATION OF THE LIGHT CURING TIP AND LIGHTMETER
}

Z. Radzi, N.H. Abu Kasim, N.A. Yahya, N.A. Abu Osman, N.L. Kassim. Relationship of the light intensity of selected light curing units with varying distance and angulation of the light curing tip and lightmeter. Annal Dent Univ Malaya 2008; 15(1): 33-39.

\section{ABSTRACT}

Background: The purpose of this study was to investigate the light intensity of selected light curing units with varying distance and angulation of the light curing tip and lightmeter.

Materials and method: Four types of light units; Spectrum 800 (Dentsply), Coltulux 3 (Coltene), Elipar FreeLight 2 (3M Espe) and Starlight Pro (Mectron) were evaluated for light intensity at various distances between the light curing tip and the radiometer Cure Rite Denstply $(0,1,3,5,10$ and 15 $\mathrm{mm})$. The light curing units were tested at right angles to the aperture of the light meter and at the angles of $45^{\circ}, 60^{\circ}$ to it at a standardized $5 \mathrm{~mm}$ distance.

Results: The highest light intensity was obtained when the tip of light curing unit was in contact with the lightmeter aperture. The light intensity decreased significantly when the light tip was placed $5 \mathrm{~mm}$, $10 \mathrm{~mm}$ and $15 \mathrm{~mm}$ away from the lightmeter aperture. However, no significant differences $(p>.05)$ were detected between $0 \mathrm{~mm}, 1 \mathrm{~mm}$ and $3 \mathrm{~mm}$. There was a decrease in light intensity when light tip was angulated at $45^{\circ}$ and $60^{\circ}$ except for Coltolux 3 .

Conclusions: The intensity of the curing light was affected by the distance between the light curing tip and the lightmeter. However, the decrease in light intensity of the light curing unit was found not to obey the inverse square law for the distances 0 to 15 $\mathrm{mm}$.

The study found that there was no significant difference between $45^{\circ}$ and $60^{\circ}$ angulation between the light curing tip and the lightmeter. However, the decrease in light intensity was significant when compared to the light tip placed perpendicular $\left(90^{\circ}\right)$ to the aperture of the light meter.

Key words: distance, angulation light curing unit, light intensity, composite resin

\section{INTRODUCTION}

Light activated composite resin is the most commonly used restorative material for anterior
Original Article

Z. Radzi ${ }^{1}$, N.H. Abu Kasim ${ }^{1}$, N.A. Yahya ${ }^{1}$,
N.A. Abu Osman ${ }^{2}$, N.L. Kassim ${ }^{3}$
${ }^{1}$ Faculty of Dentistry, University of Malaya,
50603 Kuala Lumpur, Malaysia
Email: Eamrir@um.edu.my
${ }^{2}$ Department of Biomedical Engineering,
Faculty of Engineering, University of Malaya,
50603 Kuala Lumpur, Malaysia
${ }^{3}$ Centre for Language Studies,
International Islamic University, Malaysia
Corresponding author: Dr Zamri Radzi

teeth as it fulfills the requirements of excellent esthetics and durability (1). The materials are generally supplied as a single paste which contains monomers, comonomers, filler and an initiator which is unstable in the presence of certain light such as high intensity visible light (2). These materials require the use of a specialist light source, capable of delivering radiation with appropriate characteristics to the surface of the freshly placed material in situ. Currently several types and designs of light activation unit are available for the polymerization of light activated materials such as quartz tungsten halogen (QTH), plasma arc, laser and light emitting diode (LED). The most important requirement of these light curing units is the ability to deliver high intensity radiation of the correct wavelength to the surface of the materials in order to activate polymerization $(2,3)$.

Light activation is accomplished with blue light at a peak wave length of about $470 \mathrm{~nm}$, which is absorbed usually by photo-initiator, such as camphorquinone (4). The initiation system starts the polymerization process through the formation of free radicle. When a free radicle collides with a carbon double bond $(\mathrm{C}=\mathrm{C})$ in the resin monomer, it pairs with one of the electrons of the double bond, converting the other member of the pair in to a free radicle, and thus the reaction continues. In light cured systems, a light source of $468 \mathrm{~nm}(+/-20)$ excites camphorquinone or another diaketone into a triplet state that interacts with a non-aromatic tertiary amine, such as $\mathrm{N}, \mathrm{N}$-dimethylaminoethyl methacrylate. Ideally, this process continues until all of the monomers become polymerized. Polymerization is directly related to the wavelength, intensity and time of exposure (5). 


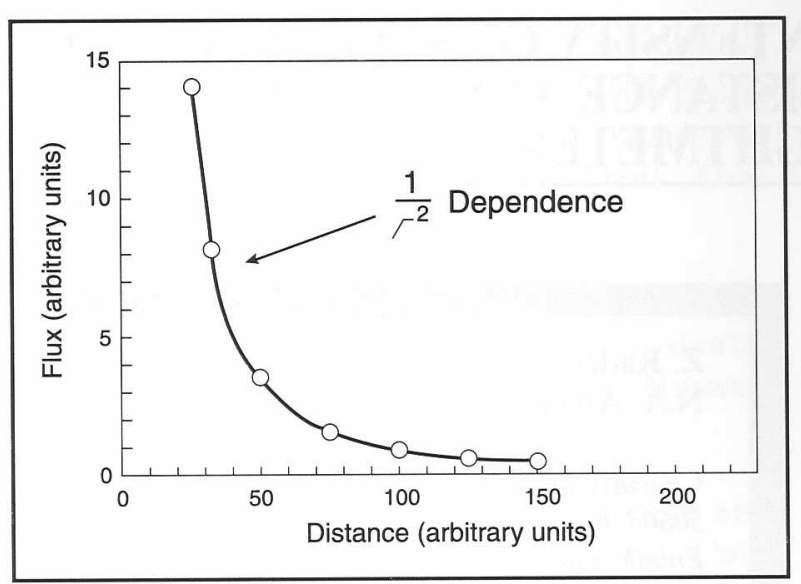

Figure 1: The relationship between Flux and Distance.

For maximum curing, which is about $50 \%$ to $60 \%$ monomer conversion, a radiant energy influx of approximately 16 joules $/ \mathrm{cm}^{2}$ is required for a 2$\mathrm{mm}$ thick layer of composite resin. This can be delivered by a $40-\mathrm{sec}$ exposure to a lamp emitting $400 \mathrm{~mW} / \mathrm{cm}^{2}$. The same result can be produced by a 20-sec exposure at $800 \mathrm{~mW} / \mathrm{cm}^{2}$, or an exposure of $\sim 13 \mathrm{sec}$ with $1200-\mathrm{mW} / \mathrm{cm}^{2}$ lamp. Thus increasing the power density of the lamp increases the rate and degree of cure (6).

The degree of polymerization also varies according to the distance from the surface of the composite to the light source. Depth of cure decreases significantly as this distance increases. The potential for activation declines exponentially as a function of the distance from the surface of the filling (5). The intensity of the light $I_{x}$ at a distance $x$ from the surface is given by the function

$$
I_{x}=I_{o} e-\mu X
$$

Where $I_{o}$ is the light intensity at the surface and $\mu$ is the absorption coefficient of the material. Since a certain level of intensity is required to cause activation it follows that light activated materials have a limited depth of cure (5).

The intensity of light observed from a source of constant intrinsic luminosity falls off as the square of the distance from the object. This is known as the inverse square law for light intensity (7).

Thus, if the distance to a light source is doubled, the intensity is decreased to $(1 / 2)^{2}$, that is equivalent to $1 / 4$ of its original value. Generally, the ratio of intensities at distances $\mathrm{d}_{1}$ and $\mathrm{d}_{2}$ are

$$
\frac{l_{1}}{l_{2}}=\frac{d_{2}^{2}}{d_{1}^{2}}
$$

Van Noort (2002) stated that the light intensity per unit surface area drops off with the inverse square of the distance between the light source and the resin (8) (Figure 2a \& 2b).

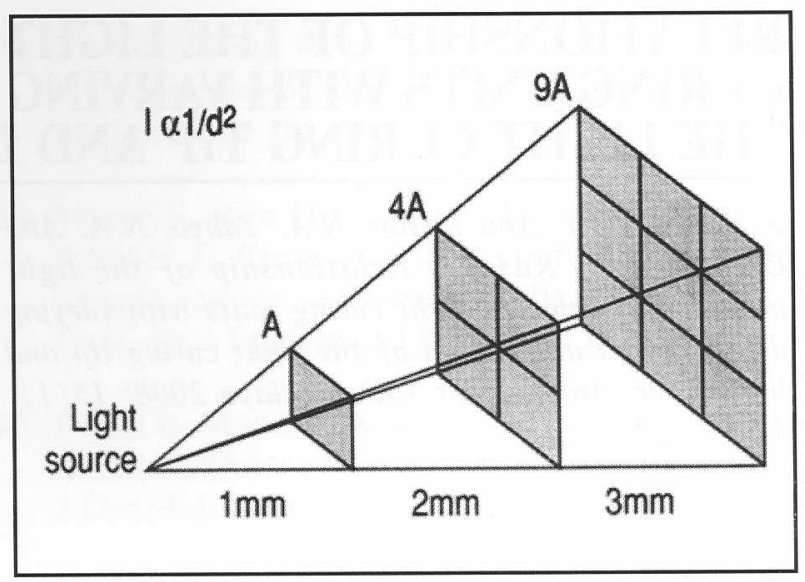

Figure 2: The relationship between intensity (I) of the light and the distance (d) from the light source to the surface.

The ideal distance of the light source from the composite is $1 \mathrm{~mm}$, with the light source positioned at the right angle to the composite surface. As the angle reduces from $90^{\circ}$, the light energy is reflected away and penetration is greatly reduced $(9,10)$. Although the $90^{\circ}$ position has always been emphasised, no study has investigated the effect of angulation although this situation is commonly seen in clinical practice.

Therefore, the purpose of this study was to investigate the effect of on the light intensity of selected light curing units with varying the distance and angulation of the light curing tip.

\section{MATERIALS \& METHOD}

Four types of light curing units; Spectrum 800 (Dentsply, USA); (Figure 3), Coltolux 3 (Coltene, USA); (Figure 4), Elipar FreeLight 2 (3M Espe, USA);(figure 5) and Starlight Pro (Mectron, USA); (Figure 6) were evaluated for light intensity at various distance between the light curing tip and a lightmeter (Cure Rite Caulk, Denstply, USA). Cure

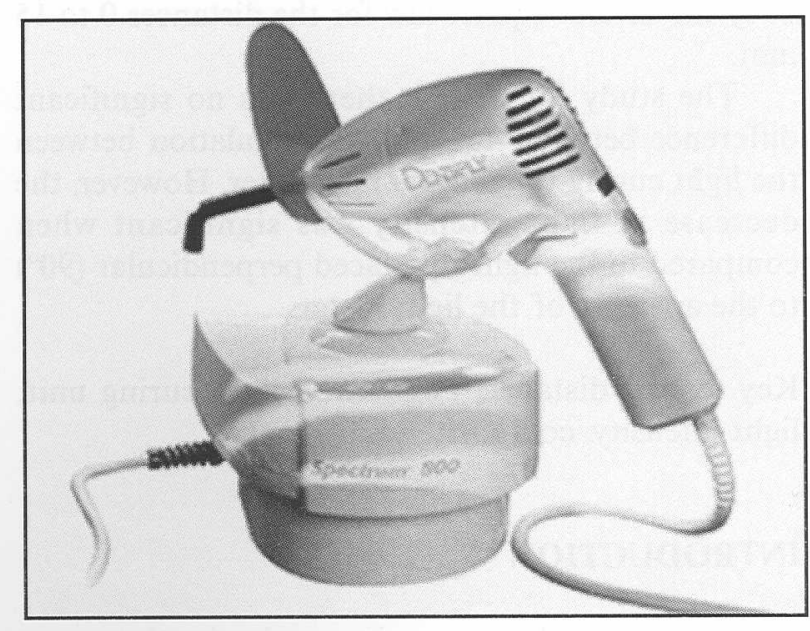

Figure 3: Spectrum 800 (Dentsply, USA). 


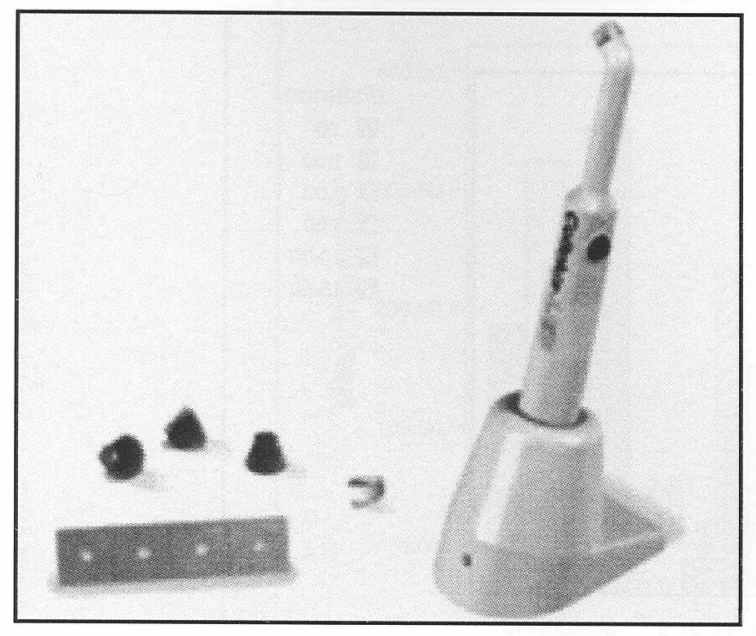

Figure 4: Coltolux 3 (Coltene, USA).

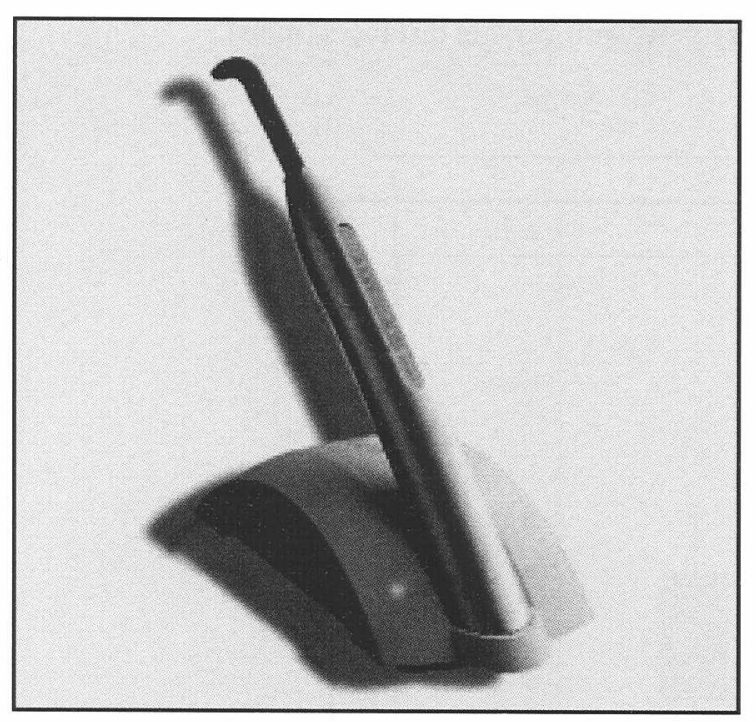

Figure 5: Elipar FreeLight 2 (3M Espe, USA).

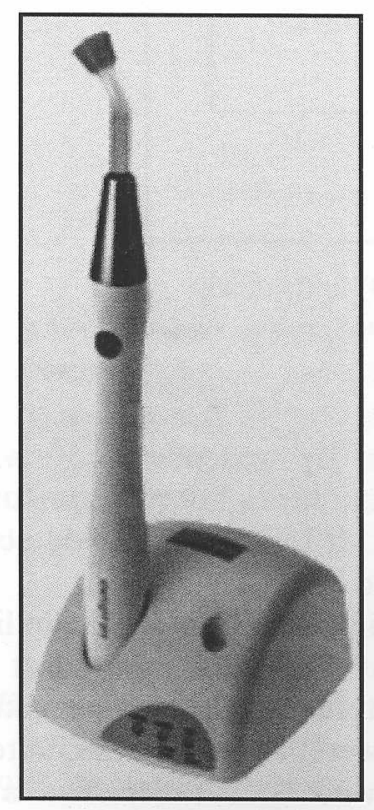

Figure 6: Starlight Pro (Mectron, USA).

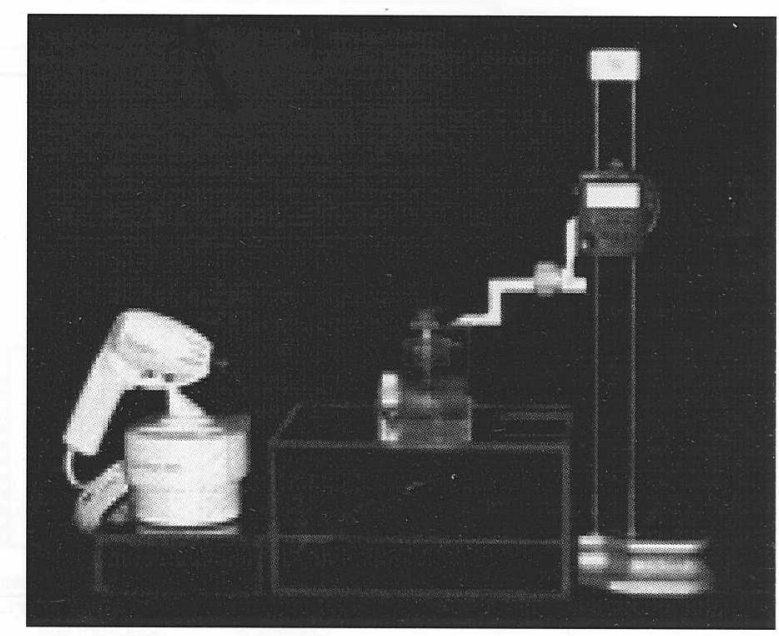

Figure 7 Curing light and Distometer.

Rite measured curing energy only in the 400 to 500 $\mathrm{nm}$ part of the spectrum and recorded the results in milliwatts per square centimeter and being able to measure a curing energy between zero to $1999 \mathrm{mw} /$ $\mathrm{cm}^{2}$ (11). All the light bulbs and reflectors of the light curing unit were new.

This distometer consisted of; a base, a sliding platform mounted on the box, a protractor, a ruler, a height gauge (Mitutoyo) and light curing holder (Figure 7).

The light curing unit was fastened to a vertical support so that the tip was parallel to the table surface. The digital visible lightmeter was fixed to the mounting table coaxially with the light tip. The light tip was angulated at $90^{\circ}$ to the light aperture and held at five different distances from it: $0 \mathrm{~mm}$ (surface contact), $1 \mathrm{~mm}, 3 \mathrm{~mm}, 5 \mathrm{~mm}, 10 \mathrm{~mm}$ and $15 \mathrm{~mm}$. These distances were standardized using the gauge height (Mitutoyo, Japan) that was attached to the distometer. The position of each light tip was adjusted to ensure the light emitted was transmitted to the centre of the lightmeter aperture. The intensity of the light source was measured in $\mathrm{mW} / \mathrm{cm}^{2}$. Each measurement of light intensity was made 5 times for 10 seconds.

In a second part of the study, the distance between the curing light tip and the light aperture was standardized at $5 \mathrm{~mm}$ and the light curing tips were angulated at $90^{\circ}, 60^{\circ}$ and $45^{\circ}$ to the lightmeter aperture. A similar set-up of the distometer was used. Each measurement was made 5 times for 10 seconds duration.

Statistical analysis was performed using TwoWay ANOVA (SPSS version 12.0).

\section{RESULTS}

Figure 8 showed that the highest light intensity was obtained when the tip of light curing unit was in contact with the lightmeter aperture. It also showed 


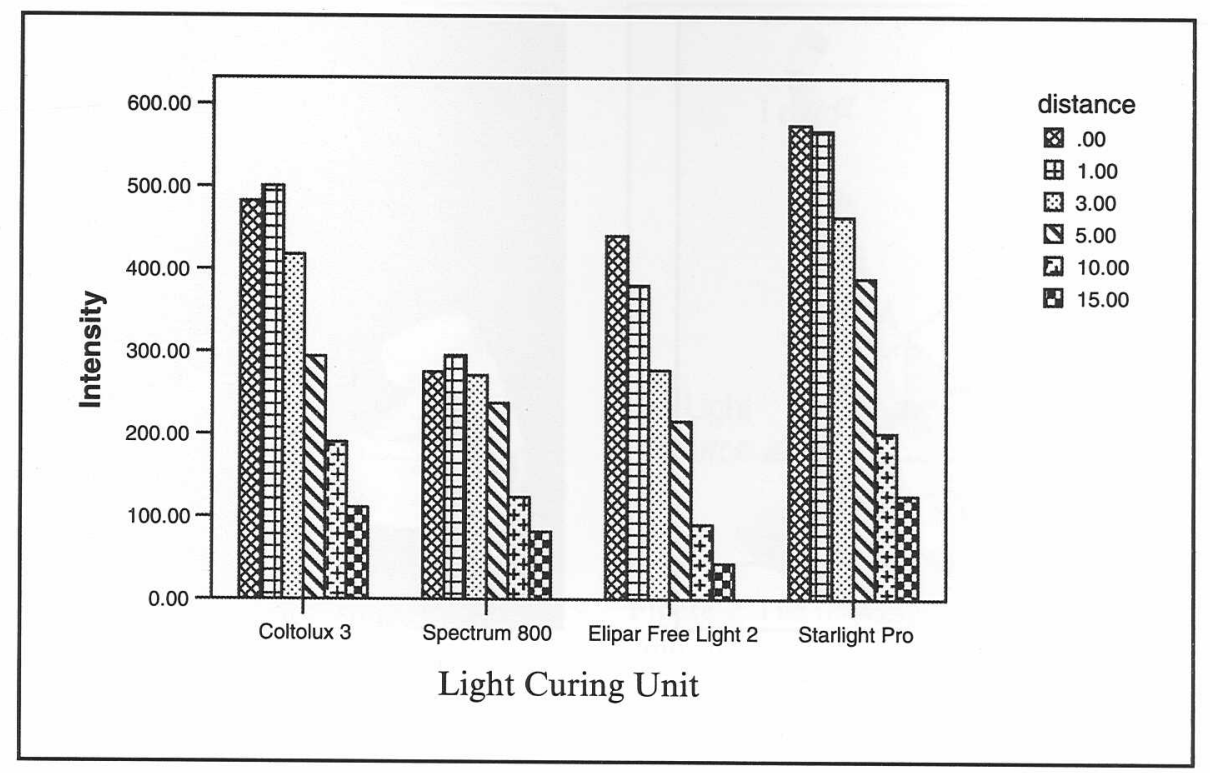

Figure 8: Bar chart: Light curing units vs Intensity units with varying distances (mms).

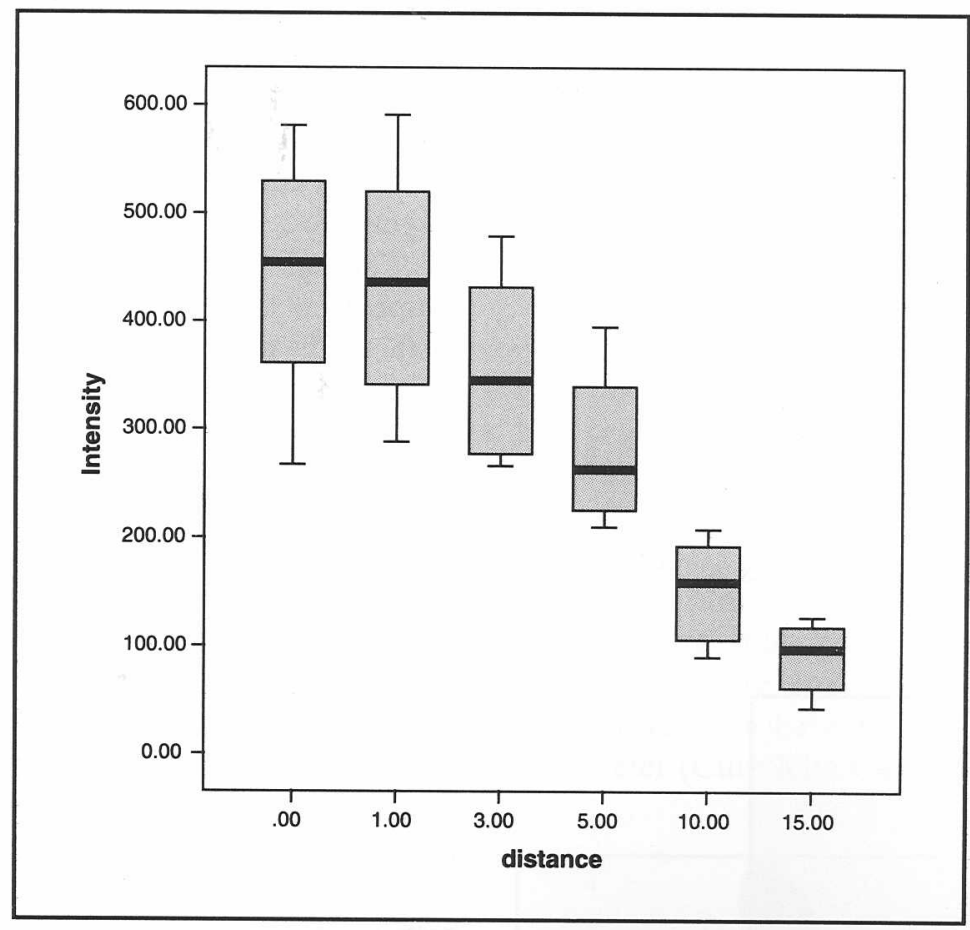

Figure 9: Box plot of mean light intensity (+/- SD) units of all test groups with varying distances $(\mathrm{mm})$.

that the intensity of all the light curing units decrease as a function of distance.

Descriptive statistics showed that all data were normally distributed. Two-way ANOVA showed that there was a significant interaction between light and distance. Dunnett's T Post Hoc tests were used to compare the differences between groups as Levene's test revealed that equal variance across all groups could not be assumed. The box plot in Figure 9 showed that light intensity decreased significantly when the light tip was placed $5 \mathrm{~mm}, 10 \mathrm{~mm}$ and $15 \mathrm{~mm}$ away from the lightmeter aperture. However, no significant differences were detected between $0 \mathrm{~mm}, 1 \mathrm{~mm}$ and $3 \mathrm{~mm}$.

Figure 10 illustrated a decrease in light intensity when the light tip was angulated at $45^{\circ}$ and $60^{\circ}$ except for Coltolux 3. Descriptive statistics showed that all data were normally distributed. Two-way ANOVA showed that there was a significant interaction between light and angulation. Dunnett's 


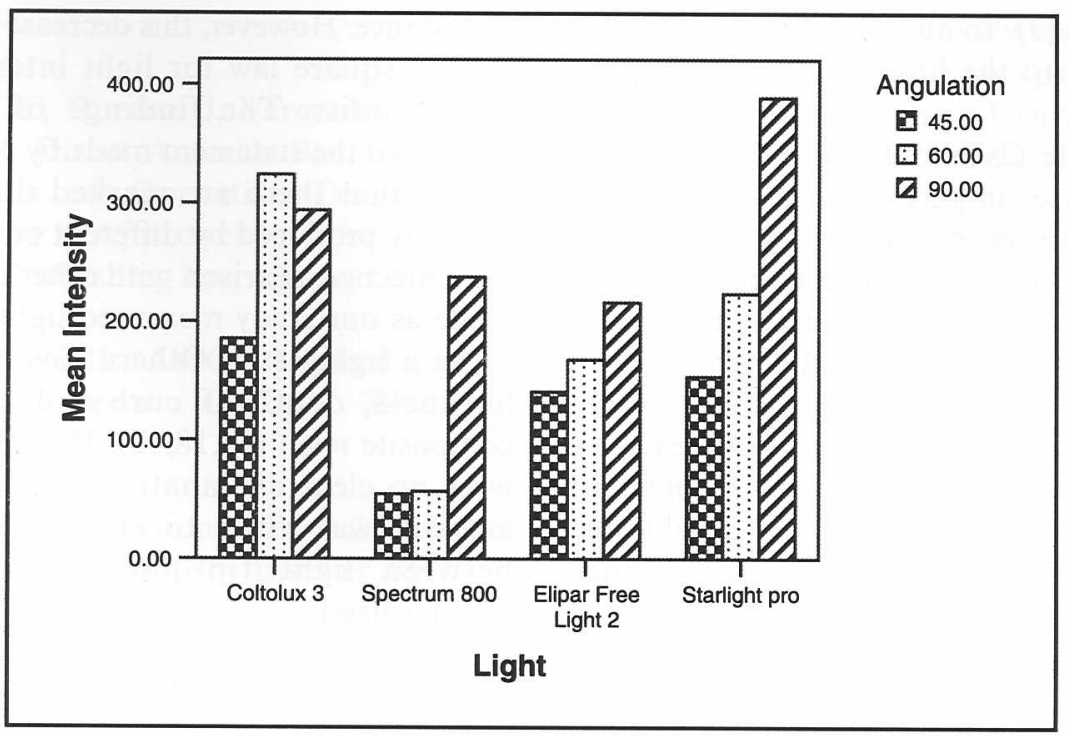

Figure 10: Bar chart: Light curing units vs Intensity (units) with different angulation of light tip.

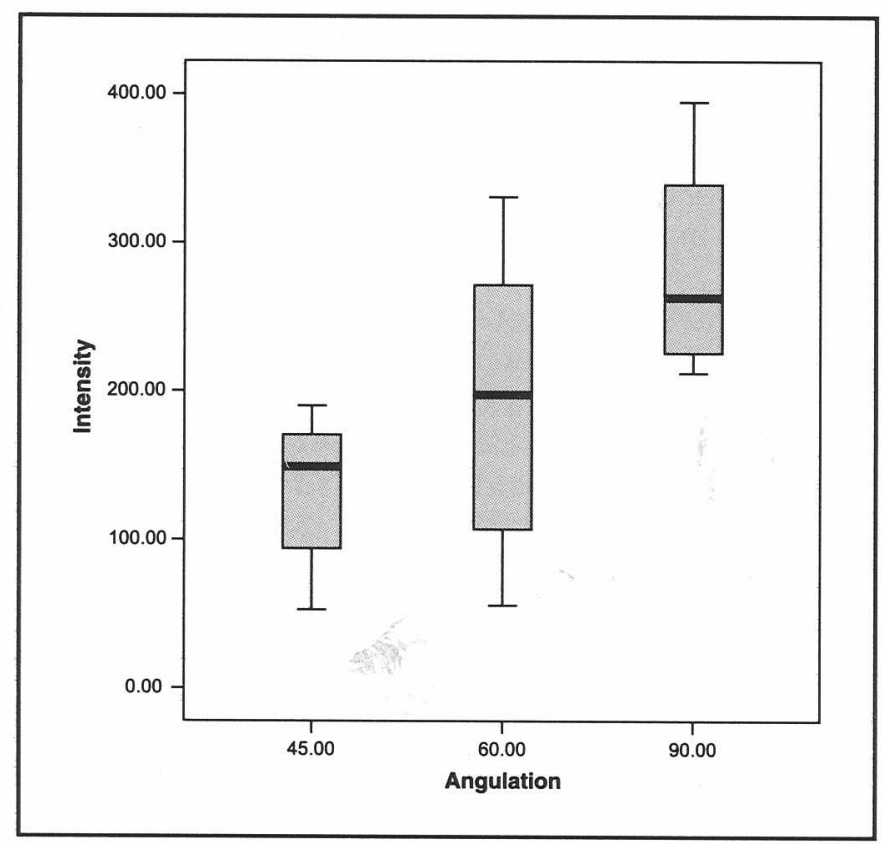

Figure 11: Box plot of light intensity (+/-SD) units mean and std deviation of all test groups with varying angulation (degrees).

T Post Hoc tests were used to compare the differences between groups as Levene's test revealed that equal variance across all groups could not be assumed. The box plot in Figure 11 shows that light intensity decreased significantly when the light tip was angulated at $45^{\circ}$ and $60^{\circ}$ to the lightmeter aperture.

\section{DISCUSSION}

In ISO 4049, light activated materials are required to be tested for sensitivity to ambient light (13).
When subjected to lighting equivalent to a dental operating light they should show no detectable change in consistency after 60 seconds exposure. After being covered with a matrix strip and exposed to the light source, polymerization is often very rapid. The ability to set rapidly after exposure to the light source is termed 'command setting' (2).

The compatibility of light sources and composite materials has been the subjects of studies and debates (2,3). Most currently available light-activated resin composite materials utilize a similar catalyst system and most light-activation units are designed to deliver radiation which has a high intensity at the 
relevant wavelength (3). In all light curing units, the light is transmitted to the hose tip by a fibreoptic bundle (14).

According to Mc Cabe and Walls (2008), there are marked differences in performance between the units with a variation in intensity ranging between 130 to 1300 lux at $470 \mathrm{~nm}$. Since depth of cure values which are supplied by manufacturers have normally been measured with a specific light source, it cannot be guaranteed that the same depth of cure could be achieved with a different light source (2).

A common light source is a quartz-tungsten halogen (QTH) bulb (14). This unit is capable of generating the required power of light output and is relatively cheap. The power output from the bulb deteriorates as the bulb ages reducing the effectiveness of the curing process. It also generates a considerable amount of heat both directly and through emissions in the infra red range of the light spectrum (2). The blue-LED light curing unit has the advantage that it only emits light within a very narrow range around $460-480 \mathrm{~nm}$. It is therefore ultra energy efficient and can be operated with a small rechargeable battery, making it portable. However, the bandwidth of the light may be so narrow that for some composites using a visible light curing process not incorporating camphoroquinone, its optimum light curing condition may lie outside the bandwidth (3)

One of the optical phenomena that are important is the light transmission through a resin composite layer. A considerable part of the irradiance light that illuminates the resin composite is reflected. The other part of the light that penetrates has the function of exciting the photoinitiator to start polymerization process as deeply as possible. But the extent of this light's penetration depends on the absorption coefficients of the resin composite's components (15). If the Naperian absorption coefficient, $1 / \alpha$, is used, the depth of penetration $(\alpha)$ is the distance at which the radiant power, $\mathrm{P}_{\lambda}^{\mathrm{o}}$, decreases to $1 / \mathrm{e}$ of its incident value, $\mathrm{P}_{\lambda}^{\circ}$, being e, the Naperian Number (16). Theoretically, if the distance were doubled to a light source, the intensity is decreased to $(1 / 2)^{2}$, that is a quarter of its original value. Therefore, the light intensity per unit surface area drops off with the inverse square of the distance between the light source and the resin (3).

The results of this study confirmed that distance has an effect on the intensity of the light at distances greater than $3 \mathrm{~mm}$ away light intensity decreased significantly when light tip was placed from the lightmeter aperture. However, no significant differences were detected between $0 \mathrm{~mm}, 1 \mathrm{~mm}$ and $3 \mathrm{~mm}$. Our study showed that the intensity recorded from all light curing units decreased as a function of distance. However, this decrease did not follow the inverse square law for light intensity for all light curing units. The findings of this study also supported the statement made by McCabe and Walls (2008) that there are marked differences in light intensity produced by different curing lights (2).

Direct comparison with other research cannot be made as our study measured light intensity directly using a lightmeter. Others have evaluated surface hardness, depth of cure and bond strength of composite resin $(17,18,19)$. However, in these, there were no clear explanations and evidence that an attempt was made to ensure that the distances between light tip and resin composite was standardized.

The findings of our study showed a decrease in light intensity when light tip is angulated to $45^{\circ}$ and $60^{\circ}$ except for Coltolux 3. In everyday clinical work the dentist invariably angulates the light curing tip when polymerizing composite resin. Sometimes angulating the light tip cannot be avoided as access to the restoration may be limited by the tooth or cavity's position. It may also be due to poor hand control of the operator or assistant. The findings of this study found that for maximum light intensity it is important to maintain $90^{\circ}$ angulation of the tip of light curing unit to the surface. Further studies need to be carried out to ascertain it effect on composite resins. Therefore the curing times recommended by the manufacturer may need to be extended whenever the tip of the light curing unit cannot be placed perpendicular $\left(90^{\circ}\right)$ to the surface of the composite resin.

\section{CONCLUSIONS}

The intensity of light curing was affected by the distance between the light curing tip and the lightmeter. However, the decrease in light intensity of the light curing unit did not obey the inverse square law for distances 0 to $15 \mathrm{~mm}$.

The study found that there was no significant difference between $45^{\circ}$ and $60^{\circ}$ angulation between the light curing tip and the lightmeter. However, the decrease in light intensity was significant when compared to the light tip being placed perpendicular $\left(90^{\circ}\right)$ to the aperture of the light meter.

\section{ACKNOWLEDGMENT}

We would like to express our appreciation to Mrs Yvonne Padmini, Miss Kasmaliza Kassim and Mr. Zaini Abdul Wahab for their invaluable contribution to this project. 


\section{REFERENCES}

1. Murchison DF, Roeters J, VargosMA, Chan, DCN. (2006). Direct Anterior Restorations in Fundamentals of Operative Dentistry. A Contemporary Approach. $3^{\text {rd }}$ Edition. Quintessence Publishing Inc, Chicago.

2. McCabe JF, Walls AWG. Applied Dental Materials, $9^{\text {th }}$ edn. Oxford, Blackwell Munksgaard 2008.

3. Van Noort R. Introduction to Dental Materials, $3^{\text {rd }}$ edn. Philadelphia, Mosby Elsevier 2007.

4. Powers JM, Sakaguchi RL. (2006) Craig's Restorative Dental Materials. Mosby Elservier.

5. McCabe JF, Walls AWG. (1998). Applied Dental Materials. $8^{\text {th }}$ Edition. Blackwell Publishing.

6. Anusavice KJ. (2003). Philips' Science of Dental Materials. Eleventh Edition. Saunders.

7. Van Noort R. (2002). Introductions to Dental Materials. Mosby-Year Book, Inc.

8. Kelsey WP, Shearer, GO, Cavel, WT, Blankenau RJ. (1987). The effects of wand positioning on the polymerization of composite resin. J Am Dent Assoc 114: 213-215.

9. Radzi Z, Yahya NA, Zamzam N, Wood DJ. (2004). Light Curing Units in Orthodontics. Annals of Dentistry 11: 13-23.

10. Intensity: the Inverse Square Law. http:// WWW.pasco.com/regources/experiments/ $1 \mathrm{abdownloads/pdfs/g} 1$ x / p hys ics / $34 \% 20$ Inverse $\% 20$ square $\% 20$ SV.pdf down loaded on 4th January 2008.
11. Cure Rite ${ }^{\mathrm{TM}}$. http://www.caulk.com/pages, products/total.cfm?prod $=\mathrm{Cure}+\mathrm{Rite}+$ $\mathrm{Visible}+\mathrm{Curing}+\mathrm{Light}+$ Meter \&req $=$. Downloaded on $2^{\text {nd }}$ February 2008.

12. Radzi Z, Yahya NA, Kasim NH, Abu Osman NA, Aziz ZA. (2006). Light Composite Distometer. Abstract University of Malaya Research and Innovation Expo.

13. ISO 4049 Dentistry: polymer-based filling, restorative and luting materials.

14. Powers JM, Wataha JC. Dental Materials, Properties and Manipulation, $9^{\text {th }}$ edn. Philadelphia, Mosby Elsevier 2008.

15. Davidson CL, de Gee AJ. Light curing units, polymerization, and clinical implications. J Adhes Dent 200; 2: 167-73.

16. Dos Santos GB, Monte Alto RV, Sampaio Filho HR, da Silva EM, Fellows CE. Light transmission on dental composites. Dental Materials 2008; 24: 571-576.

17. Rueggeberg FA, Jordan DM. (1993). Effect of light tip distance on polymerization of resin composite. Int J Prost 6: 364-370.

18. Pires JAF, Cvitko E, Denehy GE, Swift EJ. (1993). Effects of curing tip distance on light intensity and composite resin microhardness. Quintessence Int; 24: 517-521.

19. Cacciafesta V, Sfondrini MF, Scribante A, JostBrinkmann PG. (2005). Effect of light-tip distance on the shear bond strength of composite resin. Angle Orthod; 75: 386-391. 